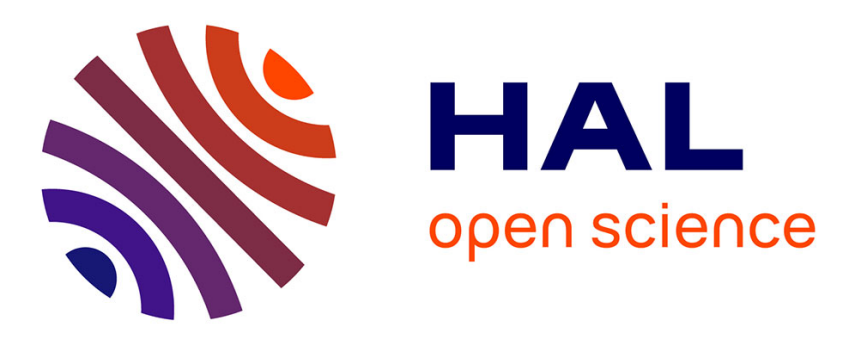

\title{
Current Harmonic Eliminations for Seven-Phase Non-sinusoidal PMSM Drives applying Artificial Neurons
}

\author{
Duc Tan Vu, Ngac-Ky Nguyen, Eric Semail, Thi Thanh Nga Nguyen
}

\section{To cite this version:}

Duc Tan Vu, Ngac-Ky Nguyen, Eric Semail, Thi Thanh Nga Nguyen. Current Harmonic Eliminations for Seven-Phase Non-sinusoidal PMSM Drives applying Artificial Neurons. The 3rd International Conference on Engineering Research and Applications (ICERA 2020), Dec 2020, Thai Nguyen, Vietnam. pp.270-279, 10.1007/978-3-030-64719-3_31 . hal-03053864

\section{HAL Id: hal-03053864 https://hal.science/hal-03053864}

Submitted on 11 Dec 2020

HAL is a multi-disciplinary open access archive for the deposit and dissemination of scientific research documents, whether they are published or not. The documents may come from teaching and research institutions in France or abroad, or from public or private research centers.
L'archive ouverte pluridisciplinaire HAL, est destinée au dépôt et à la diffusion de documents scientifiques de niveau recherche, publiés ou non, émanant des établissements d'enseignement et de recherche français ou étrangers, des laboratoires publics ou privés. 


\title{
Current Harmonic Eliminations for Seven-phase Non-si- nusoidal PMSM Drives applying Artificial Neurons
}

\author{
Duc Tan Vu ${ }^{1[0000-0001-7608-5870]}$, Ngac Ky Nguyen ${ }^{2[0000-0001-8376-6164]}$, Eric Semail ${ }^{3[0000-0001-}$ \\ 8565-1707], and Thi Thanh Nga Nguyen ${ }^{40000-0002-9800-7280]}$ \\ 1,2,3 Univ. Lille, Arts et Metiers Institute of Technology, Centrale Lille, Yncrea Hauts-de- \\ France, ULR 2697-L2EP, HESAM, F-59000 Lille, France \\ 1,4 Thai Nguyen University of Technology, Thai Nguyen, Vietnam \\ vuductan-tdhetnut.edu.vn
}

\begin{abstract}
This study is to deal with unwanted current harmonics in rotating (dq) frames of a 7-phase non-sinusoidal permanent magnet synchronous machine (PMSM) in a wye-connected winding topology. The machine is supplied by a 7leg voltage source inverter (VSI) fed by a DC-bus voltage. In control, current responses are expected to properly track their references. However, several unwanted harmonics of the non-sinusoidal back electromotive force (back-EMF) and the inverter nonlinearity generate unwanted harmonic components in d-q currents. These current harmonics cannot be nullified by controllers such as conventional proportional-integral (PI) controllers. Consequently, the current responses cannot track their references. In this study, a combination of conventional PI controllers and simple adaptive linear neurons (ADALINEs) is proposed to eliminate these current harmonics, improving current control quality of the drive. The effectiveness of the proposed control structure is verified by experimental results.
\end{abstract}

Keywords: Multiphase machine, seven-phase PMSM, non-sinusoidal backEMF, current harmonics, ADALINE, artificial intelligence.

\section{$1 \quad$ Introduction}

Electric multiphase drives have become more interesting due to their advantages over the conventional three-phase drives such as higher reliability and lower power per phase rating [1]. In an electric drive, machine design and inverter nonlinearity can affect current control quality [2,3]. Owing to the multi-reference frame theory [4], only one harmonic of back-EMF should be associated with each d-q frame. As a result, all currents and back-EMFs in d-q frames are constant, creating constant torques. It means that there are no current harmonics in d-q frames. In general, a $n$-phase machine should contain only $(n-1) / 2$ harmonics in its back-EMF. For example, a 7-phase machine has three $\mathrm{d}-\mathrm{q}$ and one zero-sequence frames. Therefore, three is the maximum number of harmonics that should exist in the back-EMF to create constant torques with constant $\mathrm{d}$-q currents. Nevertheless, because of machine design, more than one back-EMF harmonic can be associated with each d-q frame. These unwanted back-EMF harmonics cause not only current harmonics in d-q frames but also torque ripples. In addition, extra current harmonics in $\mathrm{d}-\mathrm{q}$ frames are generated by the inverter nonlinearity with 
dead-time voltages. These dead-time voltages are analyzed in [5] for inverters with different numbers of legs. To eliminate current harmonics, study [6] uses low-pass filters (LPFs) to obtain harmonics from winding currents. However, the computation is complicated. Hence, study [7] applies simple ADALINEs to compensate the unwanted back-EMFs and the dead-time voltages for 3-phase machines. For multiphase machines, there have been some studies $[8,9]$ applying either an improved model predictive control strategy or an inverse model-based disturbance observer to reduce the voltage and current harmonics for 5-phase or dual 3-phase machines. However, existing high-frequency components in [8] and calculating complications in [9] are several drawbacks.

In this study, ADALINEs, with self-learning ability, fast convergence and simplicity as discussed in $[7,10,11]$, are added to conventional PI controllers for current harmonic eliminations in d-q frames of a 7-phase non-sinusoidal PMSM drive. Current control improvements are verified with experimental results under the presence of the unwanted harmonics of back-EMF and dead-time voltages from the inverter nonlinearity.

This paper is organized as follows. The modeling of a 7-phase drive is presented in section 2. Origins of current harmonics are analyzed in section 3. Solutions are discussed in section 4. A verification with experimental results is presented in section 5 .

\section{Modeling of a seven-phase PMSM}

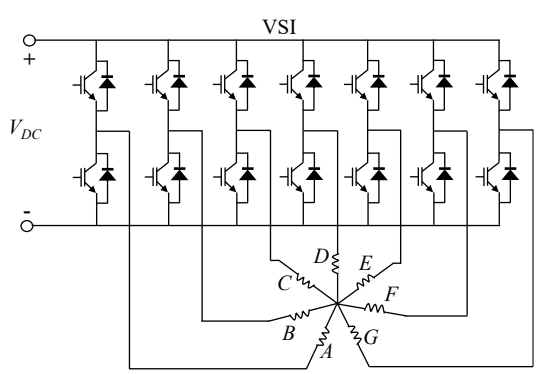

Fig. 1. Schematic diagram of a seven-phase drive in a wye-connected winding topology.

A seven-phase drive with a 7-leg VSI fed by a DC-bus voltage $V_{D C}$ is shown in Fig. 1 . Several assumptions of a 7-phase PMSM in the considered drive are described as follows: the $1^{\text {st }}, 3^{\text {rd }}$, and $9^{\text {th }}$ harmonics of its back-EMF account for highest proportions; unwanted harmonics such as $11^{\text {th }}, 13^{\text {th }}$, and $19^{\text {th }}$ have small but unneglected proportions in the back-EMF; 7 phase windings of the machine are equally shifted and wye-connected. The 7-dimensional phase voltage vector $\underline{v}$ of the machine can be expressed in (1).

$$
\underline{v}=R_{s} \underline{i}+[\boldsymbol{L}] \frac{d \underline{i}}{d t}+\underline{e}
$$

where $\underline{i}$ and $\underline{e}$ are the 7-dimensional vectors of phase currents and back-EMFs, respectively; $R_{s}$ is the resistance of one phase of stator; $[\boldsymbol{L}]$ is a 7 by 7 stator inductance matrix. 
To control the machine drive using the field-oriented control (FOC), Clarke and Park matrices are applied to convert the machine parameters from natural frame into $d-q$ frames. For example, the transformation for currents is presented in (2).

$$
\left[\begin{array}{lllllll}
i_{d 1} & i_{q 1} & i_{d 9} & i_{q 9} & i_{d 3} & i_{q 3} & i_{z}
\end{array}\right]^{T}=[\boldsymbol{P}][\boldsymbol{C}]\left[\begin{array}{llllllll}
i_{A} & i_{B} & i_{C} & i_{D} & i_{E} & i_{F} & i_{G}
\end{array}\right]^{T}
$$

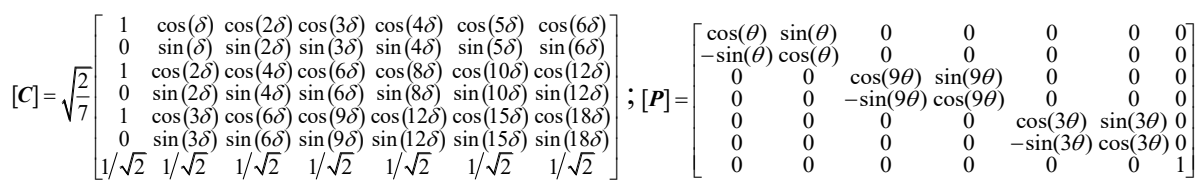

where $[\boldsymbol{C}]$ is the Clarke matrix; $\delta$ is the spatial phase shift angle $2 \pi / 7$; $[\boldsymbol{P}]$ is the Park matrix associated with the $1^{\text {st }}, 9^{\text {th }}$, and $3^{\text {rd }}$ harmonics due to the assumptions of the considered back-EMF; $\theta$ is the electrical position of the machine.

In d-q frames, the 7-phase machine is decomposed into three fictitious 2-phase machines (FM1, FM2, FM3) with decoupled frames $\left(d_{1}-q_{1}\right),\left(d_{9}-q_{9}\right)$, and $\left(d_{3}-q_{3}\right)$, respectively, and one zero-sequence machine (ZM) with reference frame $z$ [4]. Due to wyeconnected stator windings, impacts of the zero-sequence component on current control and torque performances are eliminated. A fictitious machine with its corresponding $\mathrm{d}$ $\mathrm{q}$ frame is associated with a group of harmonics as presented in Table 1.

Table 1. Fictitious machines and associated harmonics of a 7-phase machine (odd harmonics).

\begin{tabular}{lcc}
\hline Fictitious machine & Frame & Associated harmonic $\left(m \in \mathbb{N}_{0}\right)$ \\
\hline $1^{\text {st }}$ machine (FM1) & $d_{1-q_{1}}$ & $\underline{1}, \underline{13}, 15, \ldots 7 m \pm 1$ \\
$2^{\text {nd }}$ machine (FM2) & $d_{9}-q_{9}$ & $5, \underline{9}, \ldots 7 m \pm 2$ \\
$3^{\text {rd }}$ machine (FM3) & $d_{3}-q_{3}$ & $\underline{3}, \underline{11}, 17, \ldots 7 m \pm 3$ \\
Zero-sequence machine (ZM) & $z$ & $7,21, \ldots 7 m$ \\
\hline
\end{tabular}

\section{Current harmonic analyses}

According to the multi-reference frame theory [4], the back-EMF of a 7-phase machine should have only 3 harmonics $\left(1^{\text {st }}, 9^{\text {th }}\right.$, and $3^{\text {rd }}$, for example) associated with $3 \mathrm{~d}-\mathrm{q}$ frames. However, in Table 1 , two harmonics $\left(1^{\text {st }}, 13^{\text {th }}\right)$ are associated with $\left(d_{1}-q_{1}\right)$ while two harmonics $\left(9^{\text {th }}, 19^{\text {th }}\right)$ harmonics are associated with $\left(d_{9}-q_{9}\right)$. Then, two harmonics $\left(3^{\text {rd }}, 11^{\text {th }}\right)$ are associated with $\left(d_{3}-q_{3}\right)$. The back-EMF of a phase is described in (3).

$$
e_{j}=\left\{\begin{array}{l}
E_{1} \sin \left[\theta-(j-1) \frac{2 \pi}{7}\right]+E_{3} \sin \left[3\left(\theta-(j-1) \frac{2 \pi}{7}\right)+\varphi_{3}\right]+E_{9} \sin \left[9\left(\theta-(j-1) \frac{2 \pi}{7}\right)+\varphi_{9}\right]+ \\
E_{11} \sin \left[11\left(\theta-(j-1) \frac{2 \pi}{7}\right)+\varphi_{11}\right]+E_{13} \sin \left[13\left(\theta-(j-1) \frac{2 \pi}{7}\right)+\varphi_{13}\right]+E_{19} \sin \left[19\left(\theta-(j-1) \frac{2 \pi}{7}\right)+\varphi_{19}\right]
\end{array}\right\}
$$

where $e_{j}$ is the back-EMF of phase $j$ (from 1 to 7 , representing phases $A$ to $G$ ); $\left(E_{1}, E_{3}\right.$, $\left.E_{9}, E_{11}, E_{13}, E_{19}\right)$ and $\left(\varphi_{3}, \varphi_{9}, \varphi_{11}, \varphi_{13}, \varphi_{19}\right)$ are the amplitudes and phase shift angles of the harmonic components of the back-EMF. By applying the classical Clarke and Park transformations, back-EMFs in d-q frames can be expressed as follows: 


$$
\left\{\begin{array}{l}
e_{d 1}=(\sqrt{7 / 2}) E_{13} \sin \left(14 \theta+\varphi_{13}\right) \\
e_{q 1}=(\sqrt{7 / 2}) E_{1}+(\sqrt{7 / 2}) E_{13} \cos \left(14 \theta+\varphi_{13}\right) \\
e_{d 9}=(\sqrt{7 / 2}) E_{19} \sin \left(28 \theta+\varphi_{19}\right) \\
e_{q 9}=(\sqrt{7 / 2}) E_{9}+(\sqrt{7 / 2}) E_{19} \cos \left(28 \theta+\varphi_{19}\right) \\
e_{d 3}=(\sqrt{7 / 2}) E_{11} \sin \left(14 \theta+\varphi_{11}\right) \\
e_{q 3}=(\sqrt{7 / 2}) E_{3}+(\sqrt{7 / 2}) E_{11} \cos \left(14 \theta+\varphi_{11}\right)
\end{array}\right.
$$

All d-q back-EMFs in (4) are not constant because of the existing unwanted back-EMF harmonics. The back-EMFs have frequencies $14 \theta$ in $\left(d_{1}-q_{1}\right), 28 \theta$ in $\left(d_{9}-q_{9}\right)$, and $14 \theta$ in $\left(d_{3}-q_{3}\right)$. Especially, these back-EMF harmonics generate corresponding current harmonics in $\mathrm{d}-\mathrm{q}$ frames. The current harmonic amplitudes in $\mathrm{d}-\mathrm{q}$ frames depend on the harmonic distribution in the back-EMFs, and especially on the rotating speed.

The 7-leg VSI supplying the 7-phase machine creates extra current harmonics in dq frames due to its nonlinearity. Indeed, the dead time, a time interval in which both switches of one inverter leg are off, mainly causes the VSI nonlinearity. According to [5], the dead-time voltage in a phase of the VSI can be generally expressed in (5).

$$
v_{j \_ \text {dead }}=-V_{\text {dead }} \frac{4}{\pi}\left\{\begin{array}{l}
\sin \left[\theta-(j-1) \frac{2 \pi}{7}\right]+\frac{1}{3} \sin \left[3\left(\theta-(j-1) \frac{2 \pi}{7}\right)\right]+\frac{1}{5} \sin \left[5\left(\theta-(j-1) \frac{2 \pi}{7}\right)\right]+ \\
\frac{1}{9} \sin \left[9\left(\theta-(j-1) \frac{2 \pi}{7}\right)\right]+\frac{1}{11} \sin \left[11\left(\theta-(j-1) \frac{2 \pi}{7}\right)\right]+\frac{1}{13} \sin \left[13\left(\theta-(j-1) \frac{2 \pi}{7}\right)\right]+ \\
\frac{1}{15} \sin \left[15\left(\theta-(j-1) \frac{2 \pi}{7}\right)\right]+\frac{1}{17} \sin \left[17\left(\theta-(j-1) \frac{2 \pi}{7}\right)\right]+\frac{1}{19} \sin \left[19\left(\theta-(j-1) \frac{2 \pi}{7}\right)\right.
\end{array}\right\}
$$

with $V_{\text {dead }}=\frac{T_{\text {dead }}}{T_{P W M}} V_{D C}$

where $v_{j \_ \text {dead }}$ is the dead-time voltage of phase $j ; V_{\text {dead }}$ is a constant voltage; $T_{\text {dead }}$ is the dead time; $T_{P W M}$ is the switching period of the inverter; $V_{D C}$ is the DC-bus voltage. The harmonic amplitudes are inversely proportional to their orders so the considered harmonics can be up to $19 \theta$. The dead-time voltages in d-q frames are presented in (6).

$$
\left\{\begin{array}{l}
v_{d 1 \_d e a d}=-(\sqrt{7 / 2})\left[4 V_{\text {dead }} / \pi\right][1 / 13+1 / 15] \sin (14 \theta) \\
v_{q 1 \_ \text {dead }}=-(\sqrt{7 / 2})\left[4 V_{\text {dead }} / \pi\right]\{1+[1 / 13+1 / 15] \cos (14 \theta)\} \\
v_{d 9 \_ \text {dead }}=-(\sqrt{7 / 2})\left[4 V_{\text {dead }} / \pi\right][1 / 5 \sin (14 \theta)+1 / 19 \sin (28 \theta)] \\
v_{q 9 \_ \text {dead }}=-(\sqrt{7 / 2})\left[4 V_{\text {dead }} / \pi\right]\{1 / 9+[1 / 5 \cos (14 \theta)+1 / 19 \cos (28 \theta)]\} \\
v_{d 3 \_ \text {dead }}=-(\sqrt{7 / 2})\left[4 V_{\text {dead }} / \pi\right][1 / 11+1 / 17] \sin (14 \theta) \\
v_{q 3 \text { _dead }}=-(\sqrt{7 / 2})\left[4 V_{\text {dead }} / \pi\right]\{1 / 3+[1 / 11+1 / 17] \cos (14 \theta)\}
\end{array}\right.
$$

In $(6)$, the dead-time voltages in $\left(d_{1}-q_{1}\right)$ and $\left(d_{3}-q_{3}\right)$ frames have a frequency of $14 \theta$ while the voltages in $\left(d_{9}-q_{9}\right)$ have two frequencies of $14 \theta$ and $28 \theta$. Therefore, current harmonics in $\mathrm{d}-\mathrm{q}$ frames are also caused by the inverter nonlinearity with the dead-time voltages. The amplitudes of these current harmonics do not depend on the rotating speed but $V_{\text {dead }}$. Voltage $V_{\text {dead }}$ is related to $T_{\text {dead }}, T_{P W M}$, and $V_{D C}$ as described in (5). 
Finally, unwanted current harmonics in d-q frames caused by the unwanted backEMF harmonics in (4) and the dead-time voltages in (6) are summarized in Table 2.

Table 2. Current harmonics in d-q frames caused by the unwanted back-EMF harmonics and the inverter nonlinearity with dead-time voltages in a 7-phase PMSM drive.

\begin{tabular}{ccc}
\hline Frame & $\begin{array}{c}\text { Current harmonics caused by } \\
\text { unwanted back-EMF harmonics }\end{array}$ & $\begin{array}{c}\text { Current harmonics caused by } \\
\text { dead-time voltages }\end{array}$ \\
\hline$d_{1}-q_{1}$ & $14 \theta$ & $14 \theta$ \\
$d_{9}-q_{9}$ & $28 \theta$ & $14 \theta, 28 \theta$ \\
$d_{3}-q_{3}$ & $14 \theta$ & $14 \theta$ \\
\hline
\end{tabular}

\section{Eliminations of current harmonics with ADALINEs}

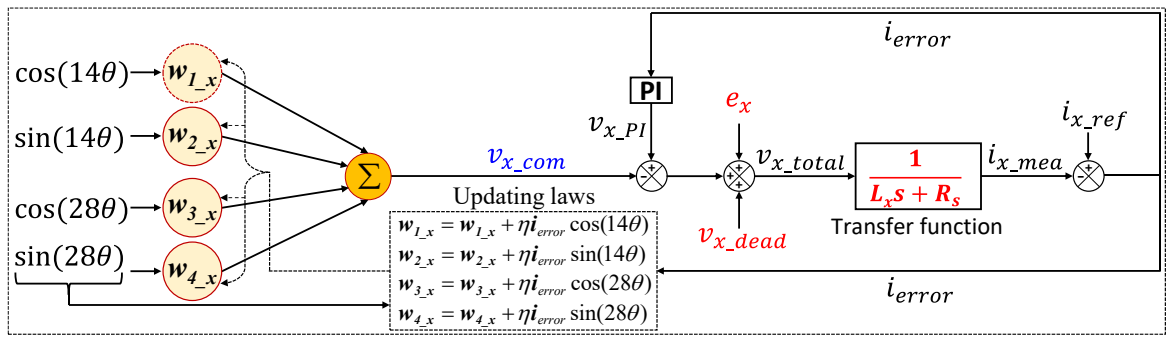

Fig. 2. The proposed control structure for current $i_{x}$ with the ADALINE compensation.

As described in Table 2, current harmonics in d-q frames have frequencies of $14 \theta$ and $28 \theta$. Due to the complexity of the experimental drive, these values need to be automatically learned in real time to correctly eliminate these current harmonics. A current control structure is proposed in Fig. 2 in which current $i_{x}$ (can be $i_{d 1}, i_{q 1}, i_{d 9}, i_{q 9}, i_{d 3}$, or $\left.i_{q 3}\right)$ is controlled by a PI controller with an adaptive compensating voltage $\left(v_{x_{-} c o m}\right)$. A fictitious machine is represented by a transfer function with inductance $L_{x}$, resistance $R_{s}$ and Laplace operator $s$. By using $v_{x_{c} \text { com }}$, all current harmonics in d-q frames described in Table 2 can be eliminated. Voltage $v_{x_{-} \text {com }}$ for current $i_{x}$ is generated by an ADALINE, hence, there are 6 ADALINEs for $6 \mathrm{~d}$-q currents $\left(i_{d 1}, i_{q 1}, i_{d 9}, i_{q 9}, i_{d 3}\right.$, or $\left.i_{q 3}\right)$ in the considered 7-phase drive. The general structure of an ADALINE in Fig. 2 is based on current harmonics in Table 2 . The ADALINE output $\left(v_{x_{\text {ccom }}}\right)$ is generally calculated from ADALINE inputs with harmonics $14 \theta$ and $28 \theta$, as described in (7).

$$
v_{x_{-} \text {com }}=\left[w_{1{ }_{-} x} \cos (14 \theta)+w_{2 \_} x \sin (14 \theta)\right]+\left[w_{3{ }_{-} x} \cos (28 \theta)+w_{4 \_} x \sin (28 \theta)\right]
$$

where harmonic weights $w_{1 \_}$and $w_{2 \_}$are associated with harmonic $14 \theta ; w_{3 \_}$and $w_{4} x$ are used for harmonic 28 $\theta$. In Fig. 2, weights of a harmonic are updated by Least Mean Square rule with learning rate $\eta$, current error $i_{\text {error }}$, and the corresponding harmonic. An increase in $\eta$ can shorten the learning time but $\eta$ should be between 0 and 1 to guarantee the weight convergence and the stability of the drive. According to Table 2 , if $x$ is $d_{1}, q_{1}, d_{3}$ or $q_{3}$, the ADALINE structure only has two weights for harmonic $14 \theta$. 
Meanwhile, if $x$ is $d_{9}$ or $q_{9}$, the ADALINE uses four weights for both harmonics $14 \theta$ and $28 \theta$. Therefore, the number of weights is optimized to avoid the calculation burden.

\section{$5 \quad$ Experimental results}

The proposed control structure in Fig. 2 is verified by an experimental drive as described in Fig. 3a and Table 3. The experimental 7-phase PMSM is mechanically connected to a load drive that is an industrial three-phase synchronous machine. The load drive is controlled to tune the rotating speed of the 7-phase PMSM. A 7-leg VSI with insulated gate bipolar transistors (IGBTs) supplies the 7-phase PMSM. Its switching frequency is set to $10 \mathrm{kHz}$. A dSPACE 1005 board with I/O interface is used to transfer PWM signals to the IGBT driver of the inverter and collect the measured data of speed and currents. The experimental 7-phase PMSM is introduced in [12]. This machine has an axial flux with double rotors. When the two rotors have different numbers of poles and spatially shifted an angle of 7 degrees, the back-EMF waveform and its specific harmonics are presented in Fig. 3b. Proportions of the back-EMF harmonics over the $1^{\text {st }}$ harmonic are $32.3 \%$ for the $3^{\text {rd }}, 12.5 \%$ for the $9^{\text {th }}, 10.3 \%$ for the $11^{\text {th }}, 5.02 \%$ for the $13^{\text {th }}, 1.98 \%$ for the $19^{\text {th }}$. The current harmonics in $d-q$ frames of the considered experimental drive have been discussed in [3]. In this study, current harmonic eliminations of the proposed control structure with ADALINE compensation are shown in Fig. 4. Current control quality is significantly improved, especially in $\left(d_{9}-q_{9}\right)$ and $\left(d_{3}-q_{3}\right)$ frames.

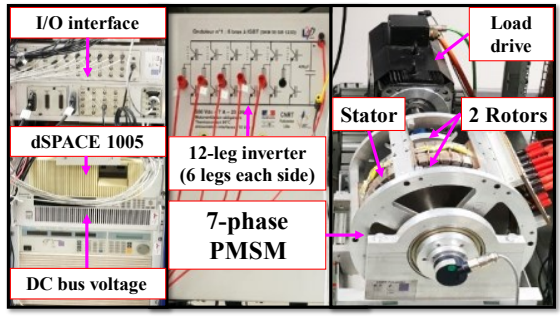

(a)

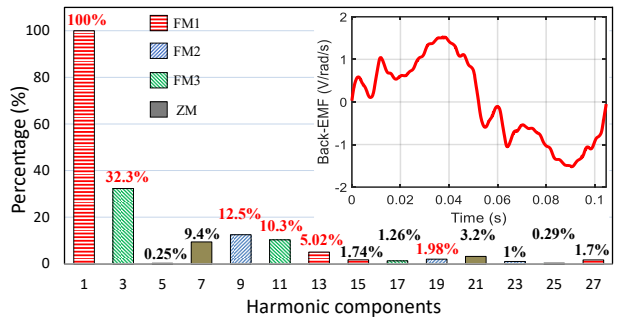

(b)

Fig. 3. The experimental drive (a), the speed-normalized back-EMF and its harmonic spectrum of the experimental 7-phase PMSM (b).

Table 3. Electrical parameters of the experimental 7-phase PMSM drive.

\begin{tabular}{lcc}
\hline Parameter & Unit & Value \\
\hline Stator resistance $R_{S}$ & $\Omega$ & 1.4 \\
Self-inductance $L$ & $\mathrm{mH}$ & 14.7 \\
Inductance $L_{d 1}=L_{q 1}$ & $\mathrm{mH}$ & 30.5 \\
Inductance $L_{d 9}=L_{q 9}$ & $\mathrm{mH}$ & 7.1 \\
Inductance $L_{d 3}=L_{q 3}$ & $\mathrm{mH}$ & 10 \\
Number of pole pairs $p$ & & 3 \\
Rated RMS current & $\mathrm{A}$ & 5.1 \\
DC-bus voltage $V_{D C}$ & $\mathrm{~V}$ & 200 \\
\hline
\end{tabular}




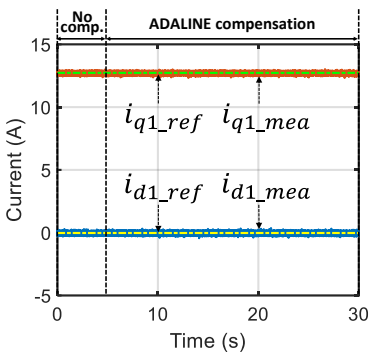

(a)

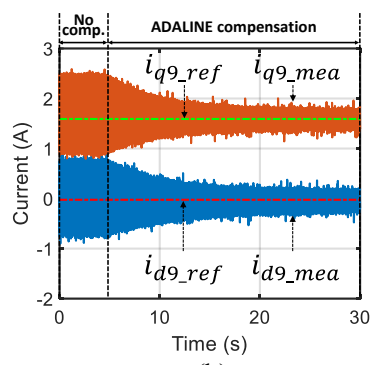

(b)

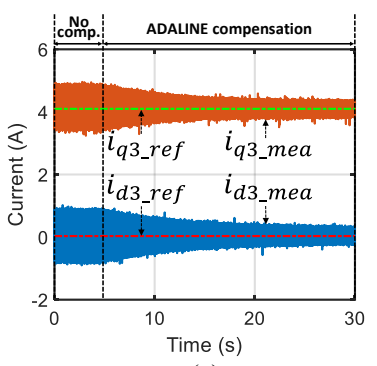

(c)

Fig. 4. (Experimental result) Currents in $\left(d_{1}-q_{1}\right)$ frame (a), currents in $\left(d_{9}-q_{9}\right)$ frame (b), currents in $\left(d_{3}-q_{3}\right)$ frame (c) without (No. comp.) and with the ADALINE compensation at $20 \mathrm{rad} / \mathrm{s}$.

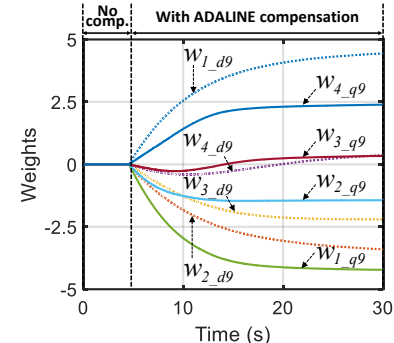

(a)

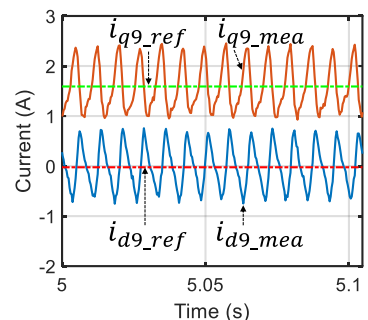

(b)

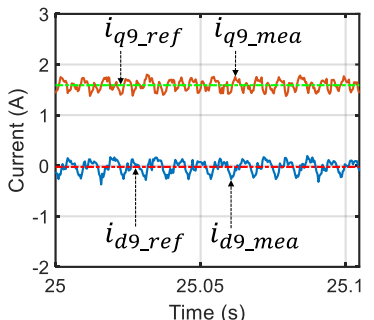

(c)

Fig. 5. (Experimental result) Weight learning within $20 \mathrm{~s}$ of the ADALINE for currents in $\left(d_{9}\right.$ $\left.q_{9}\right)$ (a), currents in $\left(d_{9}-q_{9}\right)$ frame without (b) and with (c) the ADALINE compensation at $20 \mathrm{rad} / \mathrm{s}$.

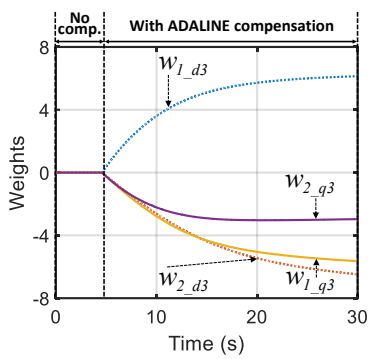

(a)

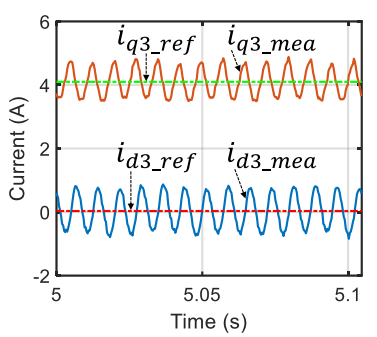

(b)

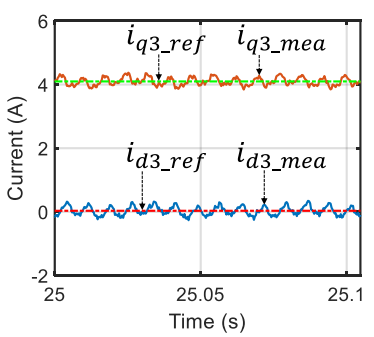

(c)

Fig. 6. (Experimental result) Weight learning within $25 \mathrm{~s}$ of the ADALINE for currents in $\left(d_{3}\right.$ $\left.q_{3}\right)$ (a), currents in $\left(d_{3}-q_{3}\right)$ without (b), and with (c) the ADALINE compensation at $20 \mathrm{rad} / \mathrm{s}$.

Figs. 5a and 6a show the weight updates with learning rate $\eta=0.0003$ for $\left(d_{9}-q_{9}\right)$ and $\eta=0.0001$ for $\left(d_{3}-q_{3}\right)$. The convergence time is about $20 \mathrm{~s}$ for $\left(d_{9-} q_{9}\right)$ and $25 \mathrm{~s}$ for $\left(d_{3^{-}}\right.$ $q_{3}$ ). Meanwhile, Figs. 5c and $6 \mathrm{c}$ describe the improvements of $d-q$ currents in one period at $20 \mathrm{rad} / \mathrm{s}$ with the ADALINE compensation compared to Figs. $5 \mathrm{~b}$ and $6 \mathrm{~b}$, respectively.

The current of phase $A$ without and with the ADALINE compensation is shown in Fig. 7a. Current waveforms in the two cases are slightly different but the root mean square current is almost unchanged at $5.1 \mathrm{~A}$. The current harmonics in natural frame generated by the unwanted back-EMFs and dead-time voltages are mostly eliminated 
as shown in Fig. 7c compared to Fig. 7b, especially the $11^{\text {th }}$ harmonic from $5.8 \%$ to $0.9 \%$. Finally, almost only the $1^{\text {st }}, 3^{\text {rd }}$, and $9^{\text {th }}$ harmonics remain in the phase current

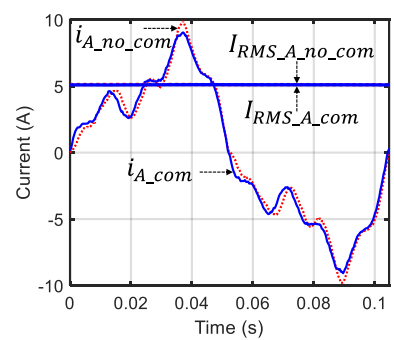

(a)

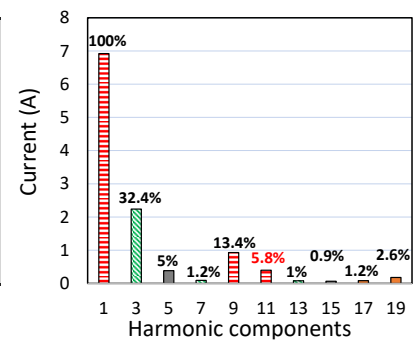

(b)

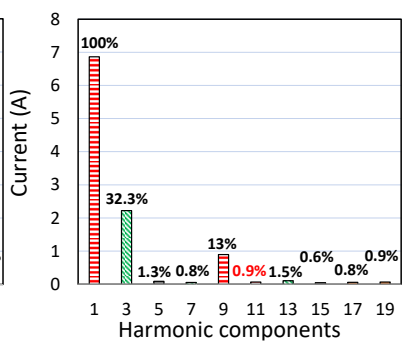

(c)

Fig. 7. (Experimental result) Phase- $A$ current without $\left(i_{A_{-} \text {no com }}\right)$ and with $\left(i_{A}\right.$ com $)$ the ADALINE compensation (a), harmonic spectrums of $i_{A_{-} \text {no_com }}(\mathrm{b})$ and $i_{A_{-} \text {com }}$ (c) at $20 \mathrm{rad} / \mathrm{s}$.

Variations of the rotating speed (from 20 to 10 and $30 \mathrm{rad} / \mathrm{s}$ ) in Fig. 8a and changes in current references in Fig. $8 \mathrm{~b}$ have modest effects on current control quality in $\left(d_{9}-q_{9}\right)$ frame. The current control performance in $\left(d_{1}-q_{1}\right)$ and $\left(d_{3}-q_{3}\right)$ frames is similar. The performance validates the dynamic responses of the proposed control structure.

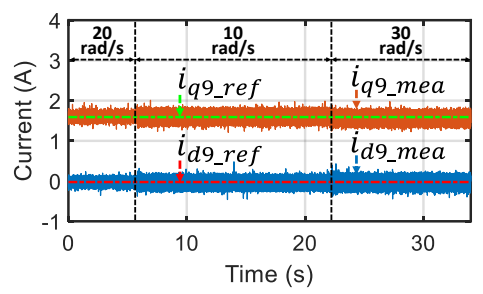

(a)

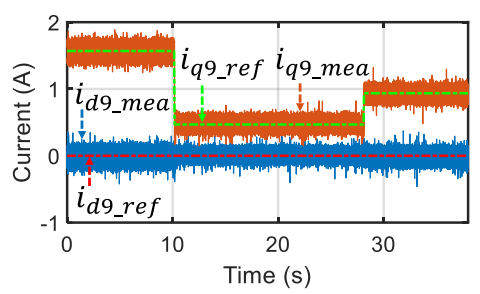

(b)

Fig. 8. (Experimental result) Current control with variable speeds (a), and variable current references $(\mathrm{b})$ in $\left(d_{9}-q_{9}\right)$ frame using the ADALINE compensation.

\section{Conclusion}

This paper has introduced an option to improve control quality of a non-sinusoidal multiphase machine drive. Simple adaptive linear neurons combined with PI controllers have eliminated most current harmonics in d-q frames caused by the unwanted backEMF harmonics and the inverter nonlinearity. Dynamic performances have been validated with sudden variations in the rotating speed or current references. The proposed control structure can be further applied to an industrial drive thanks to its adaptivity and easy implementation. 


\section{$7 \quad$ Acknowledgment}

We would like to thank Thai Nguyen University of Technology, Thai Nguyen city, Vietnam, and the CE2I project of European Union for the financial support.

\section{References}

1. F. Barrero and M. J. Duran, "Recent Advances in the Design, Modeling, and Control of Multiphase Machines Part I," IEEE Transactions on Industrial Electronics, vol. 63, no. 1, pp. 449-458, 2016.

2. J. Hwang and H. Wei, "The Current Harmonics Elimination Control Strategy for Six-Leg Three-Phase Permanent Magnet Synchronous Motor Drives," IEEE Transactions on Power Electronics, vol. 29, no. 6, pp. 3032-3040, 2014.

3. D. T. Vu, N. K. Nguyen, E. Semail, and T. J. d. S. Moraes, "Control strategies for nonsinusoidal multiphase PMSM drives in faulty modes under constraints on copper losses and peak phase voltage," IET Electric Power Applications, vol. 13, no. 11, pp. 1743-1752, 2019.

4. E. Semail, X. Kestelyn, and A. Bouscayrol, "Right harmonic spectrum for the backelectromotive force of an n-phase synchronous motor," in the 39th IEEE Industry Applications Conference, Seattle, WA, USA, 2004, vol. 1, pp. 71-78.

5. G. Grandi and J. Loncarski, "Analysis of dead-time effects in multi-phase voltage source inverters," in 6th IET International Conference on Power Electronics, Machines and Drives (PEMD 2012), 2012, pp. 1-6.

6. G. Liu, B. Chen, K. Wang, and X. Song, "Selective Current Harmonic Suppression for HighSpeed PMSM Based on High-Precision Harmonic Detection Method," IEEE Transactions on Industrial Informatics, vol. 15, no. 6, pp. 3457-3468, 2019.

7. L. Wang, Z. Q. Zhu, H. Bin, and L. M. Gong, "Current Harmonics Suppression Strategy for PMSM with Non-Sinusoidal Back-EMF Based on Adaptive Linear Neuron Method," IEEE Transactions on Industrial Electronics, pp. 1-1, 2019.

8. G. Li, J. Hu, Y. Li, and J. Zhu, "An Improved Model Predictive Direct Torque Control Strategy for Reducing Harmonic Currents and Torque Ripples of Five-Phase Permanent Magnet Synchronous Motors," IEEE Transactions on Industrial Electronics, vol. 66, no. 8, pp. 5820-5829, 2019.

9. J. Karttunen, S. Kallio, P. Peltoniemi, and P. Silventoinen, "Current Harmonic Compensation in Dual Three-Phase PMSMs Using a Disturbance Observer," IEEE Transactions on Industrial Electronics, vol. 63, no. 1, pp. 583-594, 2016.

10. H. Sediki, A. Bechouche, D. O. Abdeslam, and S. Haddad, "ADALINE approach for induction motor mechanical parameters identification," Mathematics and Computers in Simulation, vol. 90, pp. 86-97, 2013.

11. N. K. Nguyen, E. Semail, F. D. Belie, and X. Kestelyn, "Adaline Neural Networks-based sensorless control of five-phase PMSM drives," in IECON 2016 - 42nd Annual Conference of the IEEE Industrial Electronics Society, Florence, Italy, 2016, pp. 5741-5746.

12. F. Locment, E. Semail, and F. Piriou, "Design and study of a multiphase axial-flux machine," IEEE Transactions on Magnetics, vol. 42, no. 4, pp. 1427-1430, 2006. 